\title{
Pacemaker Infections Caused by Rapidly Growing Non-Tuberculous Mycobacteria: Presentation of Three Cases and Review of the Literature
}

\author{
Tejada CDJ ${ }^{1 *}$, Brown MK ${ }^{1}$, Vaughan LB $^{2}$ and Wenzel RP ${ }^{3}$ \\ ${ }^{1}$ Department of Infectious Disease, Virginia Commonwealth University, USA \\ ${ }^{2}$ Departement of Medicine and Infectious Diseases, Hunter Holmes McGuire Veterans Affairs Medical Center and Virginia Commonwealth University, USA \\ ${ }^{3}$ Department of Internal Medicine, School of Medicine, Virginia Commonwealth University, USA
}

*Corresponding author: Claudia D. Jarrin Tejada, MD, Infectious Disease, 2057 Wiltshire Rd, Berkley, MI-48072, USA, Tel: 804-928-2884; Fax: 04-628-27698; E-mail: claudiajarrin@gmail.com

Received date: June 06, 2016; Accepted date: July 20, 2016; Published date: July 25, 2016

Copyright: @ 2016 Tejada CDJ, et al. This is an open-access article distributed under the terms of the Creative Commons Attribution License, which permits unrestricted use, distribution, and reproduction in any medium, provided the original author and source are credited.

\begin{abstract}
There has been a rise in the use of cardiac pacemakers and an associated increase in the number of devicerelated infections. Although Staphylococcus aureus and coagulase-negative staphylococci are the most common causes of these infections, rapidly-growing non-tuberculous mycobacteria have occasionally been implicated. We report three cases managed at our institution and review 11 cases found in the literature. Most patients underwent device removal and were managed with more than one antibiotic for at least 4 weeks. All but one patient achieved cure. It is important to recognize these organisms as potential etiologies of pacemaker infections and to request special culture media and stains. Furthermore, antibiotic choice should be guided by susceptibility reports and, at least initially, more than one antibiotic is recommended.
\end{abstract}

Keywords: Pacemaker; Rapidly growing; Non-tuberculous mycobacteria

\section{Abbreviations \\ NTM: Non-Tuberculous Mycobacteria, MIC: Minimal Inhibitory Concentration}

\section{Introduction}

Between 1993 and 2009, 2.9 million patients received permanent pacemakers in the United States, and during that period, the use increased by $56 \%$ [1]. Over the same period, the reported attack rates of pacemaker associated infections rose. One study examining data between 1990 and 1999 reported that the rate of cardiac device infections increased from 0.94 to 2.11 per 1000 beneficiaries between 1990 and 1999 [2]. A prospective study reported that the incidence of infection after first pacemaker implantation among 46,299 consecutive pacemaker recipients between 1982 and 2007 was 1.82 per 1000 pacemaker-years [3]. Staphylococcus aureus and coagulase-negative staphylococci are commonly isolated pathogens. Other less frequently cultured organisms include gram-negative rods, fungi and Peptostreptococcus magnus [4].

There are 11 published reports of pacemaker infections caused by rapidly growing non-tuberculous mycobacteria (NTM) [5-14]. We describe the characteristics, treatment and outcomes of three cases of pacemaker infections caused by NTM and review the literature.

\section{Methods}

A literature search was conducted using Pubmed with the search terms "pacemaker infection and mycobacteria". A total of 11 cases of pacemaker infections caused by rapidly growing NTM was found. We examined the demographics of the patients and the length of time from placement of pacemakers to development of infections. We also recorded the species, antibiotics of choice, duration of treatment and outcomes.

\section{Case Histories}

\section{Case 1}

A 52 year old man with congenital complete heart block underwent dual-lead pacemaker implantation 2 years prior to presentation at an outside facility. He was admitted to our institution with nine months of progressive swelling at the pacemaker pocket site associated with clear drainage and subjective fevers and chills. On admission his temperature was $38.4^{\circ} \mathrm{C}$, pulse 72 beats per minute, respiratory rate 18 breaths per minute and blood pressure 117/72 $\mathrm{mmHg}$. He had mild tenderness over the pacemaker site with scant clear drainage. There were distant heart sounds, clear lungs and a few hyper-pigmented macules seen over his legs.

The white blood cell count was 7,000 per $\mathrm{mm} 3$, and blood cultures were negative. A CT of the chest revealed a $4 \mathrm{~cm} \times 4 \mathrm{~cm}$ nonenhancing fluid collection above the generator in the subcutaneous soft tissue, and multifocal ground-glass opacities were noted in both lower lung fields. The patient underwent extraction of the device on the day of admission, and the culture of the leads grew nontuberculous mycobacteria (NTM). A bronchoscopy with bronchoalveolar lavage yielded negative respiratory cultures for bacterial, acid-fast bacilli and fungal organisms. The pathology report noted rare bronchial cells with abundant macrophages. He had a temporary pacemaker placed a week after the explant.

Thirteen days after the extraction, speciation of mycobacteria was reported as Mycobacterium chelonae. Imipenem/cislatin $500 \mathrm{mg}$ IV every 6 hours and clarithromycin $500 \mathrm{mg}$ PO twice a day were begun empirically. In vitro studies showed susceptibility to amikacin, 
clarithromycin, linezolid and tobramycin; resistance to cefoxitin and trimethropim-sulfamethoxazole, and intermediate susceptibility to ciprofloxacin (MIC $2 \mu \mathrm{g} / \mathrm{ml}$ ). The patient completed thirty days of imipenem and clarithromycin, and he was continued with clarithromycin plus ciprofloxacin $500 \mathrm{mg}$ PO twice a day for four months more. He had close follow-up and six months later, there was no evidence of infection.

\section{Case 2}

One week after her pacemaker was placed for symptomatic bradycardia, a 64 year-old woman developed wound breakdown at her incision site. She denied any systemic symptoms such as fevers, chills, nausea, vomiting, diarrhea, night sweats or weight loss. The wound's purulent and malodorous discharge was cultured, and the device was extracted without complication. Five days after extraction, the patient's deep wound culture grew a nontuberculous mycobacterial species.

Her limited past medical history included hypertension and sinus bradycardia for which she received hydrochlorothiazide and theophylline, respectively. Aside from her pacemaker insertion and extraction, she had no history of prior surgical procedures. The patient lived alone and worked as a school bus driver. She denied having pets, recent foreign travel, injuries in salt or fresh water, or immersion in hot tubs. Her pacemaker incision site prior to her extraction had been kept dry. She denied lifetime use of tobacco, alcohol, or illicit substances.

On initial examination, her body mass index was 39.2, weight 94.2 kilograms, temperature $36.9^{\circ} \mathrm{C}$, heart rate 48 beats per minute, blood pressure 154/94 $\mathrm{mmHg}$, respiratory rate 18 breaths per minute, and an oxygen saturation of $98 \%$ while breathing ambient air. There were normal breath sounds throughout all lung fields. Her left upper chest wall revealed a $4.5 \mathrm{~cm}$ horizontal incision with a surrounding $2 \mathrm{~cm}$ of induration. The wound edges showed intact sutures with overlying colorless drainage. The overlying bandage contained dried brown exudative material. When the sutures were removed, the wound expressed a whitish discharge. Her heart had a regular rhythm without murmurs, gallops or rubs. Her abdomen was soft, non-tender, but protuberant consistent with excess adiposity.

Laboratory analyses revealed a normal basic metabolic panel and a mild normocytic anemia with a hemoglobin level of $12.8 \mathrm{~g}$. The white blood cell count was 8,000 per $\mathrm{mm}^{3}$. Routine and acid-fast blood cultures remained negative to completion, but the aerobic wound culture taken from the original infected pacer pocket grew Mycobacterium fortuitum, susceptible only to linezolid, ciprofloxacin, and amikacin. No acid-fast cultures were taken from the pacer pocket.

A transesophageal echocardiogram did not reveal any valvular involvement of this infection.

After extraction of the infected pacemaker, the patient's only symptom was a band-like bitemporal headache which improved with a lower dose of theophylline. The decision was made to hold antimycobacterial therapy due to her stability and wait for susceptibilities of the $M$. fortuitum isolate. She was subsequently started on dual therapy with linezolid and ciprofloxacin for two months followed by a 4-month course of ciprofloxacin monotherapy. Her device was successfully replaced 6 month later course without complication.

\section{Case 3}

A 55 years old woman with atrial fibrillation refractory to medication underwent a pacemaker placement at an outside hospital three months prior to admission to our institution for suspected pacemaker pocket infection. Her past medical history included endstage renal disease requiring hemodialysis, hypertension, hypothyroidism and hyperparathyroidism. She underwent an AV junction ablation three months prior to epicardial single-chamber pacemaker placement with two epicardial wires placement. The patient reported the site had healed well without incident. She denied fevers, chills, sweats, erythema, tenderness or discharge at the surgical site.

Twelve weeks following pacemaker placement the patient underwent device interrogation and was found to have an increasing right ventricular threshold. A revision of the epicardial pacing system was attempted but was unsuccessful, as the backup lead had retracted into the chest cavity. At the time of the revision, purulent material was found unexpectedly in the generator pocket.

Prior to the revision, the patient's temperature was $36.6^{\circ} \mathrm{C}$, pulse was 79 beats per minute, respiratory rate was 20 breaths per minute and blood pressure was $92 / 65 \mathrm{mmHg}$. Her lungs were clear. She had a regular rhythm with a three out of six systolic murmur. The incision site was well healed without erythema, induration, or tenderness. Her white blood cell count was 8,800 per $\mathrm{mm}^{3}$ and her hemoglobin was $10.8 \mathrm{~g}$.

After six days of incubation, deep wound cultures yielded a rapidly growing non- tuberculous mycobacterium. Eleven days later a temporary pacemaker was placed. Two days following temporary pacemaker placement the patient went back to the operating room for generator removal and excisional debridement of the leads from the thoracotomy incisions. A copious amount of purulent material poured from the pocket site with communication to the thoracotomy incision. Tissue cultures were sent and again yielded a rapidly growing nontuberculous mycobacterium, which was ultimately identified as Mycobacterium goodii. The site was irrigated with hydrogen peroxide and betadine. The existing wires were cut and the two leads were sewn to her heart.

Bacterial blood and AFB blood cultures obtained prior to antibiotic initiation showed no growth. On hospital day 17, once the Mycobacterium goodii identification was confirmed, the patient was started on ciprofloxacin $500 \mathrm{mg}$ nightly and ethambutol $1200 \mathrm{mg}$ three times per week following dialysis, plus Bactrim $900 \mathrm{mg}$ (based on trimethoprim component) three times a week after dialysis. However, drug susceptibilities revealed resistance to Bactrim. Bactrim was replaced by minocycline $100 \mathrm{mg}$ twice a day, and she continued to receive ciprofloxacin plus ethambutol. Two months following surgical excision the ethambutol was stopped and the patient was advised to continue taking minocycline and ciprofloxacin. One month later she missed her follow up appointment and ran out of medication seven weeks later. Two months after being last seen the patient returned to clinic having now been off antibiotics for two weeks. She denied any systemic signs of infection. The surgical site was intact without signs of infection as well. The decision was made not to re-institute the antibiotics and to continue to monitor patient for signs of infection. She has remained well for eleven weeks off of antibiotics with no signs of recurrence now five months following pacemaker removal. A replacement pacemaker has since been successfully placed. 
Citation: Tejada CDJ, Brown MK, Vaughan LB, Wenzel RP (2016) Pacemaker Infections Caused by Rapidly Growing Non-Tuberculous Mycobacteria: Presentation of Three Cases and Review of the Literature. J Antimicro 2: 122. doi:10.4172/2472-1212.1000122

Page 3 of 5

\section{Literature Review}

There are now 14 reported cases of NTM pacemaker infections (Tables 1 and 2) and more than half (eight) were caused by $M$. fortuitum. Other species reported include $M$. abscessus, $M$. chelonae, $M$. goodii and $M$. mageritense. In one of the reports, two species were found [12]. The first two cases were reported in 1998 [5,6] and the remaining cases [7-14] were reported since 2004. Most patients (10/14 or $71 \%$ ) presented within six months of pacemaker placement, but the range was 7 days to 20 years. The duration of symptoms varied significantly from 2 days up to 9 months. Presentation was also variable, as some cases presented with swelling and drainage while others had minimal swelling or no symptoms. One of our patients' infection was unexpected and was identified only when an increasing right ventricular threshold was noted on pacemaker interrogation. Antibiotic selection was based on susceptibilities and included the following: linezolid, clarithromycin, doxycycline and quinolones (ciprofloxacin and levofloxacin). Treatment duration ranged from 4 weeks to 6 months, and all but three cases required extraction of the pacemaker. There was only one patient who died with amikacininduced acute kidney injury [5]. The remaining patients achieved cure.

\begin{tabular}{|c|c|c|c|c|c|c|}
\hline Year & $\begin{array}{l}\text { Age } \\
\text { (years) }\end{array}$ & Gender & Comorbidities & $\begin{array}{l}\text { Length of time } \\
\text { from } \\
\text { PM placement to } \\
\text { infection }\end{array}$ & Symptoms & Reference \\
\hline 1998 & 68 & M & & 20 years & $\begin{array}{l}\text { purulent discharge and erythematous area } \\
\text { from generator pocket }\end{array}$ & 5 \\
\hline 1998 & 74 & M & Unknown & 13 days & $\begin{array}{l}\text { fever, pain and purulent discharge from } \\
\text { generator pocket }\end{array}$ & 6 \\
\hline 2004 & 62 & $\mathrm{~F}$ & $\begin{array}{l}\text { Idiopathic } \\
\text { cardiomyopathy }\end{array}$ & 9 months & $\begin{array}{l}\text { fever, pain and mild erythema at } \\
\text { pacemaker site }\end{array}$ & 7 \\
\hline 2004 & 53 & $\mathrm{~F}$ & $\begin{array}{l}\text { Coronary artery disease, } \\
\text { smoking, COPD }\end{array}$ & 2 weeks & purulent drainage at the pocket site & 8 \\
\hline 2006 & 80 & M & $\begin{array}{l}\text { Myocardial infarction, } \\
\text { symptomatic bradycardia }\end{array}$ & 18 days & $\begin{array}{l}\text { fever, purulent discharge at the pacemaker } \\
\text { pocket }\end{array}$ & 9 \\
\hline 2006 & 78 & $\mathrm{~F}$ & Sick sinus syndrome & 6 months & $\begin{array}{l}\text { swelling and discomfort over the } \\
\text { pacemaker pocket followed by fever and } \\
\text { erosion of pacemaker generation from the } \\
\text { pocket with purulent discharge }\end{array}$ & 10 \\
\hline 2007 & 84 & $\mathrm{~F}$ & Unknown & 2 months & $\begin{array}{l}\text { heart failure, fever, pain and erythema at } \\
\text { the pacemaker pocket }\end{array}$ & 11 \\
\hline 2007 & 78 & $\mathrm{~F}$ & Tachy-brady syndrome & 4 months & $\begin{array}{l}\text { wound infection -symptoms were not } \\
\text { specified }\end{array}$ & 12 \\
\hline 2007 & 77 & $\mathrm{~F}$ & $\begin{array}{l}\text { Diabetes, coronary artery } \\
\text { disease, sick sinus syndrome }\end{array}$ & 3 weeks & $\begin{array}{l}\text { wound infection -symptoms were not } \\
\text { specified }\end{array}$ & 12 \\
\hline 2009 & 15 & $\mathrm{~F}$ & Ventricular septal defect & 7 weeks & $\begin{array}{l}\text { purulent discharge from surgical wound } \\
\text { with erythema and fever }\end{array}$ & 13 \\
\hline 2009 & 23 & M & $\begin{array}{lll}\text { Mitral and tricuspid } & \text { valve } \\
\text { insufficiency and } & \text { atrio- } \\
\text { ventricular block } & & \end{array}$ & 8 days & $\begin{array}{l}\text { fever, spontaneous disunion of abdominal } \\
\text { wound with purulent discharge }\end{array}$ & 14 \\
\hline 2013 & 52 & M & Congenital heart block & 2 years & $\begin{array}{l}\text { swelling at the pacemaker pocket site with } \\
\text { clear discharge }\end{array}$ & Case 1 \\
\hline 2013 & 64 & $\mathrm{~F}$ & Sinus Bradycardia & 7 days & $\begin{array}{l}\text { swelling at the pacemaker pocket site with } \\
\text { clear discharge }\end{array}$ & Case 2 \\
\hline 2014 & 55 & $\mathrm{~F}$ & $\begin{array}{l}\text { Atrial fibrillation, hypertension, } \\
\text { ESRD, hypothyroidism }\end{array}$ & 3 months & $\begin{array}{l}\text { increasing RV threshold, otherwise } \\
\text { asymptomatic }\end{array}$ & Case 3 \\
\hline
\end{tabular}

Table 1: Characteristics of patients with NTM infections.

\begin{tabular}{|l|l|l|l|l|l|}
\hline $\begin{array}{l}\text { Duration of } \\
\text { Symptoms }\end{array}$ & Species & Treatment & $\begin{array}{l}\text { Duration of } \\
\text { Treatment }\end{array}$ & $\begin{array}{l}\text { Device } \\
\text { removal }\end{array}$ & $\begin{array}{l}\text { Outcome } \\
\text { Reference }\end{array}$ \\
\hline 4 months & M. abscessus & $\begin{array}{l}\text { clarithromycin, cefoxitin and } \\
\text { amikacin }\end{array}$ & 5 weeks & Yes \\
\hline
\end{tabular}


Citation: Tejada CDJ, Brown MK, Vaughan LB, Wenzel RP (2016) Pacemaker Infections Caused by Rapidly Growing Non-Tuberculous Mycobacteria: Presentation of Three Cases and Review of the Literature. J Antimicro 2: 122. doi:10.4172/2472-1212.1000122

Page 4 of 5

\begin{tabular}{|l|l|l|l|l|l|l|}
\hline 2 days & $\begin{array}{l}\text { M. chelonae, } \\
\text { fortuitum }\end{array}$ & gentamicin and ofloxacin & 1 month & Yes & Cured \\
\hline 1 month & M. fortuitum & doxycycline and ciprofloxacin & 6 months & Yes & Cured & 7 \\
\hline Unknown & M. abscessus & clarithromycin & 6 months & Yes & Cured & 8 \\
\hline 1 week & M. fortuitum & ciprofloxacin and clarithromycin & 6 weeks & No & Cured & 9 \\
\hline 3 months & M. fortuitum & $\begin{array}{l}\text { linezolid (two weeks), } \\
\text { clarithromycin and levofloxacin }\end{array}$ & 6 months & Yes & Cured & 10 \\
\hline 5 days & M. fortuitum & levofloxacin & 3 months & Yes & Cured & 11 \\
\hline Unknown & M. fortuitum & $\begin{array}{l}\text { linezolid (two weeks), } \\
\text { clarithromycin and levofloxacin }\end{array}$ & 6 months & Yes & Cured & 12 \\
\hline Unknown & M. mageritense & levofloxacin & 6 months & No & Cured & 12 \\
\hline M. fortuitum & M. goodie & clarithromycin and ciprofloxacin & 6 months & Yes & Cured & 13 \\
\hline 9 monsths & M. chelonae & clarithromycin and ciprofloxacin & 6 months & Yes & Cured & Case 1 \\
\hline 7 days & M. fortuitum & $\begin{array}{l}\text { linezolid and ciprofloxacin } \\
\text { months), ciprofloxacin alone } \\
\text { months) }\end{array}$ & 6 months & Yes & Cured & Case 2 \\
\hline Asymptomatic & M. goodie & ethambutol (2 months), & 3.75 months & Yes & Cured & Case 3 \\
\hline
\end{tabular}

Table 2: Initial presentation of non-tuberculous mycobacteria pacemaker infections.

\section{Discussion}

Rapidly growing NTM are non-pigmented organisms that are recovered in the microbiology laboratory within 7 days on normal media [15] and can be misinterpreted as Gram positive bacilli [10]. They are ubiquitous in the environment and are isolated more frequently in the hospital setting, colonizing water fountains, bronchoscopes and surgical devices linked to pulmonary, post-surgical and cutaneous infections [16-18]. Disseminated disease is uncommon but can occur in patients who are on dialysis or immunosuppressed. The organisms are reported to be resistant to chlorine and other detergents [19].

M. chelonae, M. fortuitum and M. abscessus are among the most common pathogenic rapidly growing NTM causing pacemakerassociated infections (78\% of patients). They are intrinsically resistant to typical antituberculous agents, and their susceptibility patterns are unpredictable, which is why we suggest reassessing empiric treatment after susceptibilities return.

While non-tuberculous mycobacteria are infrequent causes of pacemaker infections, these organisms need to be considered in patients with long-standing infections and/or recurrent infections with negative results on routine bacterial cultures. With several cases of NTM pacemaker infections that occurred over the past ten years, it would be worth considering these organisms as emerging pathogens in patients with device infections. It is unclear whether these infections had a source in the community or in the hospital. In the absence of known health care associated clusters, we suspect an environmental source in the community. Furthermore, due to the not uncommon misinterpretation problems in some Microbiology laboratories, clinicians should remember to obtain acid-fast bacilli cultures when there is concern for device infection. One of the key findings in the review of 14 cases is that cure can be achieved in a matter of six months or less in many cases with targeted antibiotics and device removal.

\section{References}

1. Greenspon AJ, Patel JD, Lau E, Ochoa JA, Frisch DR, et al. (2012) Trends in permanent pacemaker implantation in the United States from 1993 to 2009: increasing complexity of patients and procedures. J Am Coll Cardiol 60: 1540-1545.

2. Cabell $\mathrm{CH}$, Heidenreich $\mathrm{PA}, \mathrm{Chu} \mathrm{VH}$, Moore CM, Stryjewski ME, et al. (2004) Increasing rates of cardiac device infections among Medicare beneficiaries: 1990-1999. Am Heart J 147: 582-586.

3. Johansen JB, Jørgensen OD, Møller M, Arnsbo P, Mortensen PT, et al. (2011) Infection after pacemaker implantation: infection rates and risk factors associated with infection in a population-based cohort study of 46299 consecutive patients. Eur Heart J 32: 991-998.

4. Sohail MR, Uslan DZ, Khan AH, Friedman PA, Hayes DL, et al. (2007) Risk factor analysis of permanent pacemaker infection. Clin Infect Dis 45: 166-173.

5. Cutay AM, Horowitz HW, Pooley RW, Van Horn K, Wormser GP (1998) Infection of epicardial pacemaker wires due to Mycobacterium abscessus. Clin Infect Dis 26: 520-521.

6. Verghese S, Mullaseri A, Padmaja P, Subhadra AC, Cherian KM (1998) Pacemaker implant site infection caused by atypical mycobacteria. Indian Heart J 50: 201-202.

7. Sharma S, Tleyjeh IM, Espinosa RE, Costello BA, Baddour LM (2005) Pacemaker infection due to Mycobacterium fortuitum. Scand J Infect Dis 37: 66-67.

8. Kessler AT, Kourtis AP (2004) Mycobacterium abscessus as a cause of pacemaker infection. Med Sci Monit 10: CS60-CS62. 